\title{
Lipoic Acid Decreases the Viability of Breast Cancer Cells and Activity of PTP1B and SHP2
}

\author{
ALICJA KUBAN-JANKOWSKA, MAGDALENA GORSKA-PONIKOWSKA and MICHAL WOZNIAK
}

Department of Medical Chemistry, Medical University of Gdansk, Gdansk, Poland

\begin{abstract}
Background: Protein tyrosine phosphatases PTPIB and SHP2 are potential targets for anticancer therapy, because of the essential role they play in the development of tumors. PTP1B and SHP2 are overexpressed in breast cancer cells, thus inhibition of their activity can be potentially effective in breast cancer therapy. Lipoic acid has been previously reported to inhibit the proliferation of colon, breast and thyroid cancer cells. Materials and Methods: We investigated the effect of alpha-lipoic acid (ALA) and its reduced form of dihydrolipoic acid (DHLA) on the viability of $M C F-7$ cancer cells and on the enzymatic activity of PTP $1 B$ and SHP2 phosphatases. Results: ALA and DHLA decrease the activity of PTP1B and SHP2, and have inhibitory effects on the viability and proliferation of breast cancer cells. Conclusion: ALA and DHLA can be considered as potential agents for the adjunctive treatment of breast cancer.
\end{abstract}

Breast cancer is one of the most common female tumors worldwide. Breast cancer therapy includes surgery, radiotherapy or adjuvant chemotherapy. The development of breast cancer is associated with numerous disorders of tyrosine phosphorylation pathways (1).

Protein tyrosine phosphatase PTP1B dephosphorylates tyrosine kinases essential for the induction of breast cancer, i.e. HER1/EGFR, Src, JAK and STAT. PTP1B phosphatase is overexpressed in breast cancer cells and triggers the growth of a tumor (2). PTP1B phosphatase inhibitors are promising compounds for treating metabolic diseases, i.e. type 2 diabetes, obesity and metabolic syndromes. Protein tyrosine phosphatase SHP2 is overexpressed in breast cancer

This article is freely accessible online.

Correspondence to: Alicja Kuban-Jankowska, Medical Chemistry Department, Medical University of Gdansk, Debinki 1, 80-210 Gdansk, Poland. Tel: +48 583491450, Fax: +48 583491456, e-mail: alicjakuban@gumed.edu.pl

Key Words: Breast cancer, lipoic acid, ALA, DHLA, PTP1B, SHP2. cell lines, and usually provided by oncogenic signaling functions to promote growth factors and cytokines. Additionally SHP2 mutations have been found in breast cancer cells. Due to oncogenic implications of SHP2, inhibition of these phosphatases can produce a favorable effect in anticancer therapy (3). Due to the key part of protein tyrosine phosphatases in cancer biology, they might constitute promising targets for the development of new anticancer diagnostic and therapeutic strategies (4).

Previous studies have shown that fatty acids may be natural inhibitors of pro-oncogenic tyrosine phosphatase SHP2 (5). Important seems to be the fact that fatty acids have recently begun playing a role in the design of treatment of numerous diseases, with particular focus on cancer. Previous results confirmed that the selected carboxylic acids, i.e. octanoic acid, in comparison to hydrogen peroxide, possess significantly higher binding affinity to bind in the PTPs active site and can be strong inhibitors of PTPs (6).

Lipoic acid (LA) is a short-chain fatty acid, an organosulfur compound derived from octanoic acid. LA can be synthesized in the human body, but it can also be absorbed from the diet. Alpha-lipoic acid (ALA), also known as thioctic acid, can be reduced to dihydrolipoic acid (DHLA) (Figure 1). Both compounds, ALA and its reduced form DHLA, are powerful antioxidants (7). Recent studies suggested the possibility of lipoic acid as a potential anticancer agent and confirmed that LA can inhibit cell proliferation of, among others, breast, thyroid or colon cancer cells (8-10). Herein we present the studies on the effect of alpha-lipoic acid (ALA) and its reduced form of dihydrolipoic acid (DHLA) on the viability of MCF-7 breast cancer cells. We, also, compared the impact of ALA and DHLA on the enzymatic activity of PTP1B and SHP2 phosphatases.

\section{Materials and Methods}

Reagents. Phosphatases PTP1B (No. SRP0215) and SHP2 (No. SRP0217) were obtained from Sigma Aldrich, Schnelldorf, Germany. MCF-7 cell line was purchased from The European Collection of Cell Cultures (ECACC). Alpha-lipoic acid (No. T5626), dihydrolipoic acid (T8260), cell media, supplements and 


\section{alpha-lipoic acid} $(A L A)$<smiles>O=C(O)CCCC[C@@H]1CCSS1</smiles>

(oxidized form) dihydrolipoic acid (DHLA)

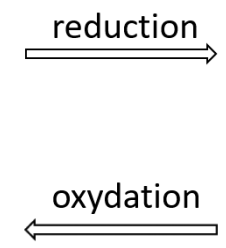

(reduced form)

Figure 1. Alpha-lipoic acid can be reduced to dihydrolipoic acid.

other reagents were obtained from Sigma Aldrich. Cell proliferation assay kit was obtained from BioAssay Systems.

Cell culture. The cells were cultured in DMEM medium supplemented with $10 \%$ fetal bovine serum, $100 \mu \mathrm{g} / \mathrm{ml}$ penicillin/streptomycin and $2 \mathrm{mM}$ L-glutamine. The culture was maintained at $37^{\circ} \mathrm{C}$ and in an atmosphere containing $5 \% \mathrm{CO}_{2}$. The cell culture density was kept to maximum $1 \times 10^{6}$ cells $/ \mathrm{ml}$. At least every two days the medium was replaced with the fresh one, and the cells were counted and reseeded to maintain the recommended density.

Cell viability test. The cells $\left(1 \times 10^{6}\right.$ cells $\left./ \mathrm{mL}\right)$ untreated (control) or treated with solutions of ALA and DHLA after the appropriate incubation time were suspended in solution of $5 \mathrm{mg} / \mathrm{ml} \mathrm{MTT}(3-[4,5-$ dimethylthiazol-2-yl]-2,5-diphenyltetrazolium bromide) in DMEM without phenol red. The $100 \mu \mathrm{l}$ samples were incubated for 3 to 4 $\mathrm{h}$ at $37^{\circ} \mathrm{C}$ in 96 -well plates. When the purple precipitate was clearly visible under the microscope, $100 \mu \mathrm{l}$ of DMSO were added to each well and the plate with cover was left in the dark for $15 \mathrm{~min}$. The absorbance at $590 \mathrm{~nm}$ was determined using a microplate reader.

Fluorescent assay for cell proliferation. The cells $\left(1 \times 10^{6}\right.$ cells $\left./ \mathrm{mL}\right)$ untreated (control) or treated with solutions of ALA and DHLA after the appropriate incubation time were suspended in solution of CellQuantiBlue reagent of resazurin. The $200-\mu 1$ samples were incubated for $1-5 \mathrm{~h}$ at $37^{\circ} \mathrm{C}$ in 96 -well plates. The fluorescence intensity of highly fluorescent product (resorufin) was measured using a fluorescence reader (excitation wavelength $=530-570 \mathrm{~nm}$, emission wavelength $=590-620 \mathrm{~nm}$ ).

PTP1B, SHP2 and CD45 activity assay. The solutions of the recombinant PTP1B and SHP2 phosphatase were prepared in $10 \mathrm{mM}$ HEPES buffer $\mathrm{pH}$ 7.4. The final concentration of phosphatases in reaction samples was $1.5 \mu \mathrm{g} / \mathrm{ml}(3.3 \mathrm{nM})$. The enzymes were untreated (control) or treated with solutions of oxidized and reduced lipoic acids. The assay was performed in 96well microplates, and the final volume of each sample was $200 \mu \mathrm{L}$. The enzymatic activity of phosphatases was measured at $37^{\circ} \mathrm{C}$ at $405 \mathrm{~nm}$ on a microplate reader Jupiter (Biogenet) using DigiRead
Communication Software (Asys Hitech $\mathrm{GmbH}$ ), using $2 \mathrm{mM}$ chromogenic substrate para-nitrophenyl phosphate (pNPP).

Statistical analysis. The experiments were performed at least three times. The data were applied and analyzed with GraphPad Prism (GraphPad Software, v.4, La Jolla, CA, USA). Statistical analyses were performed using ANOVA combined with Tukey's test or T test combined with Wilcoxon test. The data were expressed as means $\pm \mathrm{SD}$. Differences between means were considered significant for $p<0.05$.

\section{Results}

ALA and DHLA effect on MCF-7 breast cancer cell viability and proliferation. To evaluate the effect of ALA and DHLA on the viability of breast cancer cells, we tested the MCF-7 cell line. We found that ALA and DHLA are able to decrease cell viability in concentration dependent manner. After $24 \mathrm{~h}$ of treatment, the viability of cells was significantly $(p<0.001)$ decreased by $100,500 \mu \mathrm{M}$ ALA and DHLA (Figure 2). Fifty $\mu \mathrm{M}$ ALA have no impact on cell viability, whereas $50 \mu \mathrm{M}$ DHLA has an inhibitory effect $(p<0.05)$.

To evaluate the impact of ALA and DHLA on breast cancer cells after longer exposition we treated cells for $72 \mathrm{~h}$ with $100 \mu \mathrm{M}, 1 \mathrm{mM}$ ALA and DHLA. We observed that both compounds significantly $(p<0.001)$ decreased the cell viability (Figure 3A). We measured the effect of ATA and DHLA on cell proliferation with fluorescence assay and we found that both compounds significantly $(p<0.001)$ decreased the cell proliferation of MCF-7 cells (Figure 3B). After $72 \mathrm{~h}$ incubation time ALA has a slightly stronger inhibitory effect on MCF-7 cell proliferation than DHLA (Figure 3B).

Inhibitory effect of ALA and DHLA on enzymatic activity of $P T P 1 B, S H P 2$ phosphatases. In the next step, we examined the effect of ALA and DHLA on enzymatic activity of 


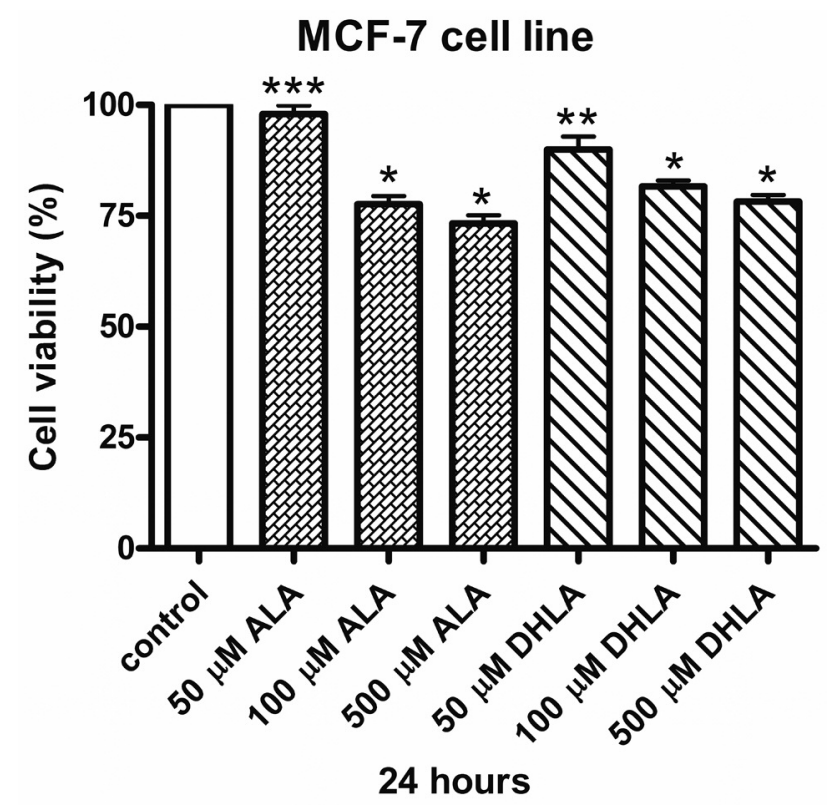

Figure 2. Cell viability of MCF-7 breast cancer cell line after treatment for $24 h$ with 50, 100, $500 \mu M$ alpha-lipoic acid (ALA) and dihydrolipoic acid (DHLA) measured with MTT-based cell viability test. Data are presented as percent of the control viability (100\%, cells not treated), mean $\pm S D(n=3)$. One-way Anova test combined with Tukey test. $*$ Means significantly different from control $(p<0.001)$.**Means significantly different from control $(p<0.05)$. ***Means not significantly different from control $(p<0.05)$.

protein tyrosine phosphatases PTP1B and SHP2. In order to assess the inhibitory effect of ALA and DHLA on PTP1B and SHP2 phosphatases we performed an enzymatic activity assay of recombinant PTPs after treatment and $30 \mathrm{~min}$ incubation with tested compounds. We found that ALA and DHLA are able to decrease the enzymatic activity of PTP1B and SHP2 in concentrations in the micromolar range (Figure 4). The inhibition of phosphatases was concentrationdependent. 10-100 $\mu \mathrm{M}$ ALA and DHLA induce only a slight effect on enzymatic activity of PTP1B, while ALA and DHLA in concentrations more than $300 \mu \mathrm{M}$ have a significant inhibitory impact (Figure 4A and B). $10 \mathrm{mM}$ ALA and DHLA induced high inactivation of PTP1B.

Similar results we observed for recombinant SHP2 phosphatase (Figure 4C and D). ALA and DHLA in concentrations exceeding $300 \mu \mathrm{M}$ caused significant inhibition of enzymatic activity of phosphatase SHP2 (Figure 4C and D).

Calculations of $I_{50}$ values of ALA and DHLA on PTPIB, SHP 2 and CD45 phosphatases. To compare the influence of ALA and DHLA on various protein tyrosine phosphatases we calculated $\mathrm{IC}_{50}$ values of one-domain non-receptor PTP1B,
Table I. Inhibitory properties of alpha-lipoic acid (ALA) and dihydrolipoic acid (DHLA) to PTP1B, SHP2 and CD45 phosphatases presented as $I C_{50}$ values. $I C_{50}$ values were determined from a plot presenting inhibitor concentration versus percentage of the enzymatic activity measured as absorbance with pNPP substrate after $30 \mathrm{~min}$ incubation with inhibitors, at substrate concentration equal to Km value. Data are presented as an estimated concentration from the plot.

\begin{tabular}{lcc}
\hline \multicolumn{3}{c}{ Calculated $\mathrm{IC}_{50}$ values } \\
\hline Phosphatase & ALA & DHLA \\
\hline PTP1B & $1.4 \pm 0.07 \mathrm{mM}$ & $4.8 \pm 0.24 \mathrm{mM}$ \\
SHP2 & $8.3 \pm 0.42 \mathrm{mM}$ & $6.5 \pm 0.32 \mathrm{mM}$ \\
CD45 & $6.5 \pm 0.33 \mathrm{mM}$ & $5.9 \pm 0.29 \mathrm{mM}$ \\
\hline
\end{tabular}

SHP2 phosphatases and two-domain receptor CD45 (Table I).

We used different concentrations of ALA an DHLA and 30 min incubation time of phosphatases with tested compounds. We calculated $\mathrm{IC}_{50}$ values based on a plot presenting ALA and DHLA concentration versus percentage of the enzymatic activity of recombinant PTP1B, SHP2 and CD45 measured as absorbance with pNPP substrate. The pNPP concentration for $\mathrm{IC}_{50}$ calculations was equal to $\mathrm{Km}$ value determined for PTP1B, SHP2 and CD45, where Km value is defined as substrate concentration at which enzyme activity is at half-maximal.

The obtained results indicated that ALA and DHLA are able to decrease the enzymatic activity of selected phosphatases and are effective in a concentration in a range of about 1-8 mM (Table I). We observed the tendency that alpha-lipoic acid was the most effective, and that PTP1B phosphatase was the most sensitive for ALA induced inhibition (Table I).

\section{Discussion}

Breast cancer is one of the most common female tumors and usually presents with complicated etiology and multiple organ metastasis. The number of breast cancer cases is still growing in recent years. Because of the genetic and environmental factors, breast cancer is more often becoming a problem of younger women (11).

Recent studies have shown that lipoic acid and its analogs may have a significant impact in cancer metabolism and can be considered in chemotherapy (12). Lipoic acid was found to increase apoptosis in, among others, breast, colon, lung or leukemic cancer cell lines $(8,13-15)$. Recent studies showed that anti-proliferative action of lipoic acid can be possibly due to the activation of pyruvate dehydrogenase, thus inducing the suppression of aerobic glycolysis and induction of cell death (16). 
A

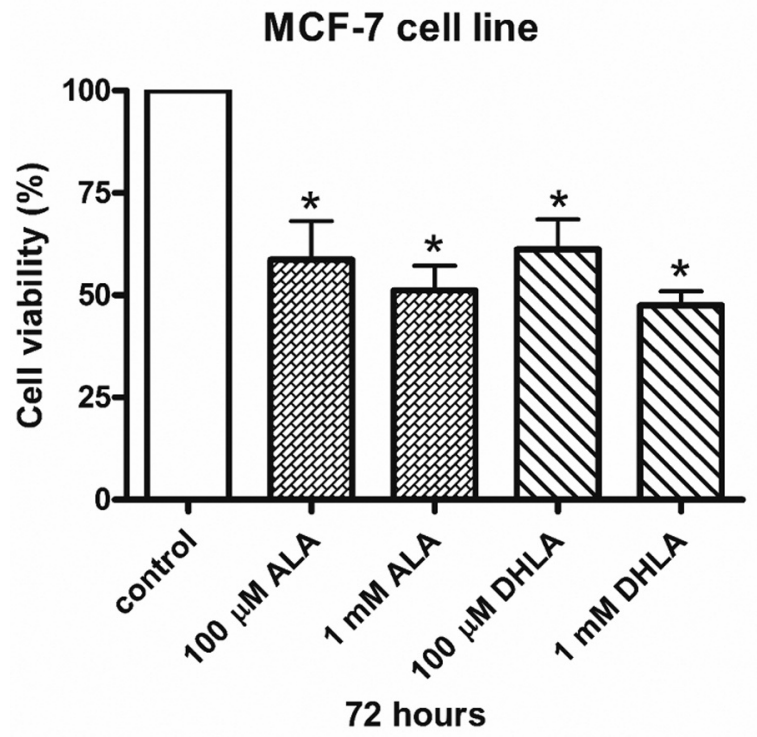

B

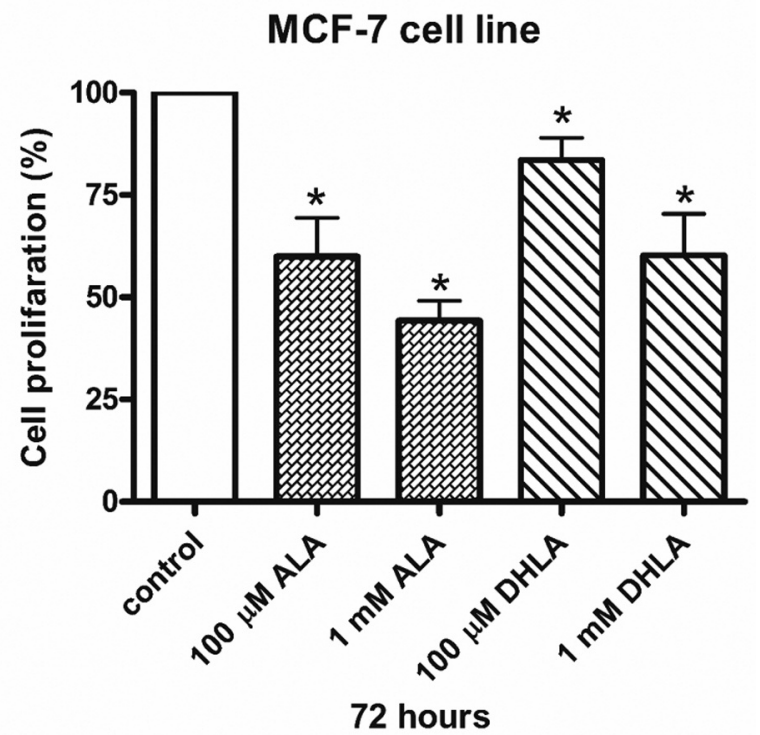

Figure 3. (A) Cell viability of MCF-7 breast cancer cell line after treatment for $72 \mathrm{~h}$ with $1 \mathrm{mM}, 100 \mu \mathrm{M}$ alpha-lipoic acid (ALA) and dihydrolipoic acid (DHLA) measured with MTT-based viability test. Data presented as percent of the control viability (100\%, cells not treated), mean $\pm S D(n=3)$. One-way Anova test combined with Tukey test. *Means were significantly different from control $(p<0.001)$. (B) Cell proliferation of MCF-7 breast cancer cell line after treatment for $72 \mathrm{~h}$ with $1 \mathrm{mM} 100 \mu \mathrm{M}$ alpha-lipoic acid (ALA) and dihydrolipoic acid (DHLA) measured with resazurin-based fluorescent cell proliferation test. Data are presented as a percent of the control (100\%, cells not treated), mean $\pm S D(n=3)$. One-way Anova test combined with Tukey test. *Means were significantly different from control $(p<0.001)$.

Rapidly-dividing cancer cells have a higher iron requirement than properly-dividing cells. Tumor cells are, thus, sensitive to decrease of iron (17). This enables the use of iron chelators as a new concept for the design of cancer treatments. Lipoic acid is known to possess metal-chelating properties, which could be important mechanism of action of LA in anticancer treatment (18).

In this study, we found an inhibitory effect of ALA and DHLA on cancer cell viability using the MCF-7 breast cancer cell line model. These findings indicate that lipoic acid can be considered a potential agent for breast cancer therapy. LA can be used combined with other drugs as an adjuvant therapy. Many anticancer drugs induce generation of reactive oxygen species (ROS) (19). Both ALA and DHLA have been reported to scavenge a variety of oxygen species (7) and, apart from inhibitory effect on tumor cells, they could scavenge free radicals and ROS produced by systemic anticancer agents.

There are evidences that ALA might be useful agent in chemoprevention of obesity-related cancers (20). ALA was already experimentally utilized in treatment of diabetic, as ALA induces reduction of oxidative stress and causes improvement in nerve function (21). It is important that, phosphatase PTP1B is involved in pathogenesis of type-2 diabetes and obesity. PTP1B has become a major target for pharmacological modulation in the therapy of these pathologies. It was found that mice lacking PTP1B phosphatase are healthy, and have enhanced sensitivity to insulin (22). Protein tyrosine phosphatases are implicated also in cancer development (4). PTP1B is considered as drug target in colon cancer (23) and, as well as SHP2 phosphatase, in breast cancer (1). Our studies showed that ALA and DHLA are able to inhibit protein tyrosine phosphatases PTP1B and SHP2.

In summary, we herein showed that ALA and DHLA decrease the viability of breast cancer cells and have inhibitory effects on enzymatic activity of potentially oncogenic phosphatases PTP1B and SHP2. Our studies indicate that ALA and DHLA can be potential agents for the treatment of breast cancer, possibly as an adjuvant therapy with other known systemic therapeutic agents. Recent studies have shown that lipoic acid used as a dietary supplement was well tolerated, with no significant toxicity or interaction (24). Lipoic acid can be considered as a supplement to systemic anticancer treatment to enhance the inhibitory effect on tumor cells and to protect from ROS generated by anti-cancer agents.

\section{Conflicts of Interest}

The Authors declare that they have no conflict of interest. This article does not contain any studies with human participants or animals performed by any of the authors. 
A

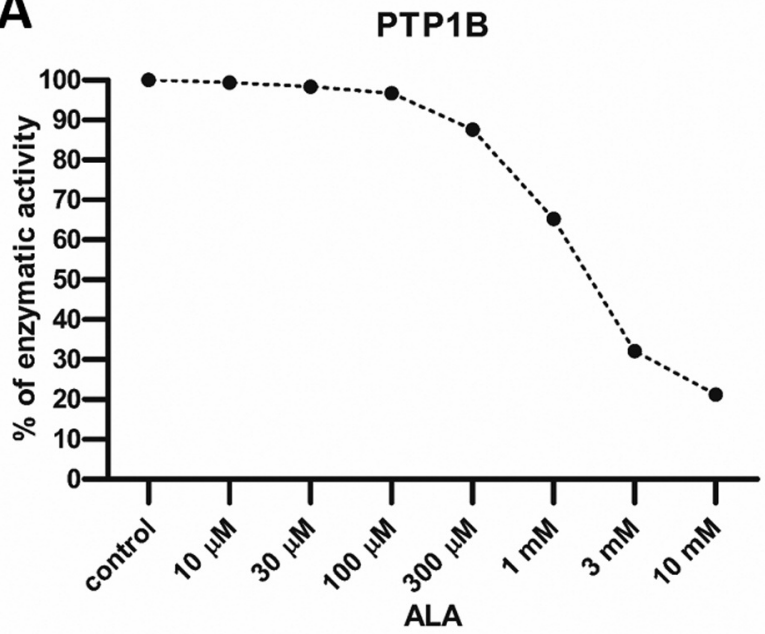

C

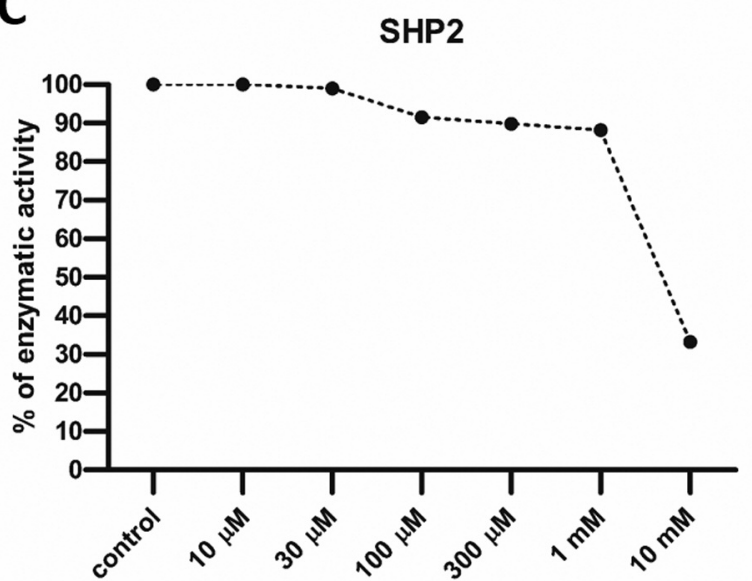

ALA
B

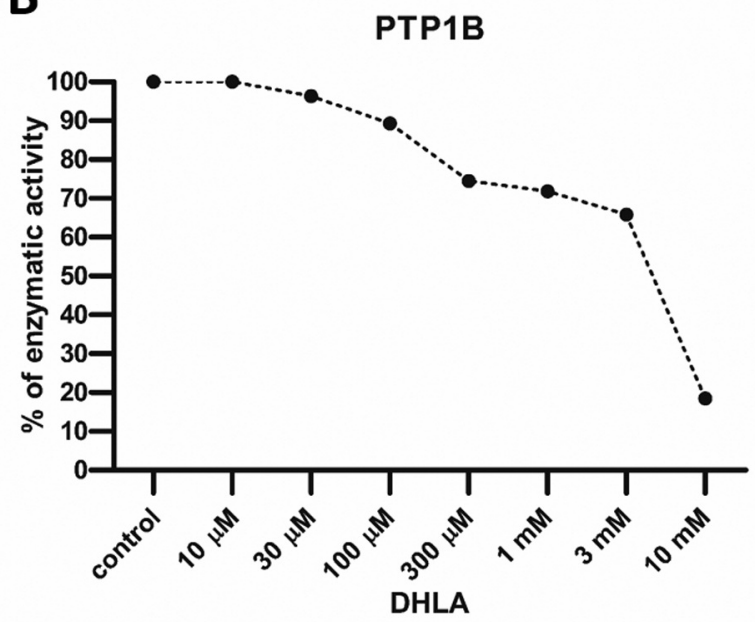

D

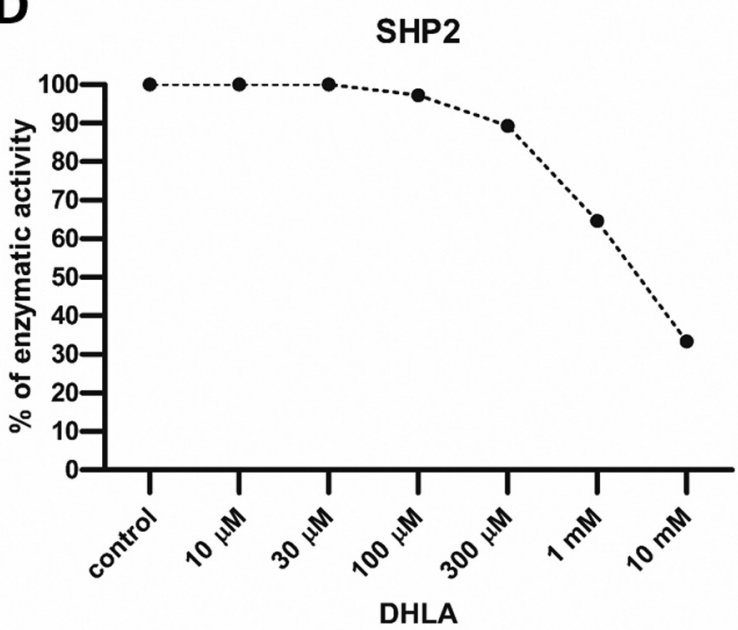

Figure 4. (A) Enzymatic activity of PTP1B phosphatase after 30 min of treatment with different concentrations of alpha-lipoic acid (ALA). (B) Enzymatic activity of PTP1B phosphatase after 30 min of treatment with different concentrations of dihydrolipoic acid (DHLA). (C) Enzymatic activity of SHP2 phosphatase after 30 min of treatment with different concentrations of alpha-lipoic acid (ALA). (D) Enzymatic activity of SHP2 phosphatase after $30 \mathrm{~min}$ of treatment with different concentrations of dihydrolipoic acid (DHLA). Data are presented as percent of the control enzymatic activity $(100 \%$, cells not treated $)$, mean $\pm S D(n=3)$.

\section{Funding}

The Authors acknowledge financial support from the project IP2015 038774 from Polish Ministry of Science and Higher Education.

\section{References}

1 Nunes-Xavier CE, Martin-Perez J, Elson A and Pulido R: Protein tyrosine phosphatases as novel targets in breast cancer therapy. Biochim Biophys Acta 1836: 211-226, 2013.

2 Balavenkatraman KK, Aceto N, Britschgi A, Mueller U, Bence $\mathrm{KK}$, Neel BG and BentiresAlj M: Epithelial protein-tyrosine phosphatase $1 \mathrm{~B}$ contributes to the induction of mammary tumors by HER2/Neu but is not essential for tumor maintenance. Mol Cancer Res 9: 1377-1384, 2011.
3 Aceto $\mathrm{N}$ and Bentires-Alj $\mathrm{M}$ : Targeting protein-tyrosine phosphatases in breast cancer. Oncotarget 3: 514-515, 2012.

4 Scott LM, Lawrence HR, Sebti SM, Lawrence NJ and Wu J: Targeting Protein Tyrosine Phosphatases for Anticancer Drug Discovery. Curr Pharm Des 16: 1843-1862, 2010.

5 Liu D, Kong G, Chen QC, Wang G, Li J, Xu Y, Iin T, Tian Y, Zhang X, Yao X, Feng G, Lu Z and Chen H: Fatty acids as natural specific inhibitors of the proto-oncogenic protein Shp2. Bioorg Med Chem Lett 21: 6833-6837, 2011.

6 Kuban-Jankowska A, Gorska M, Tuszynski JA, Churchill CD, Winter P, Klobukowski M and Wozniak M: Inactivation of Protein Tyrosine Phosphatases by Peracids Correlates with the Hydrocarbon Chain Length. Cell Physiol Biochem 36: 1069-1083, 2015.

7 Biewenga GP, Haenen GR and Bast A: The pharmacology of the antioxidant lipoic acid. Gen Pharmacol 29: 315-331, 1997. 
8 Li BJ, Hao XY, Ren GH and Gong Y: Effect of lipoic acid combined with paclitaxel on breast cancer cells. Genet Mol Res 14: 17934-17940, 2015.

9 Jeon MJ, Kim WG, Lim S, Choi H-J, Sim S, Kim TY, Shong YK and Kim WB: Alpha lipoic acid inhibits proliferation and epithelial mesenchynal transition of thyroid cancer cells. Mol Cel Endocrinol 419: 113-123, 2015.

10 Damnajanovic I, Kocic G, Najman S and Stojanovic S: Chemopreventive potential of alpha lipoic acid in the treatment of colon and cervix cancer cell lines. Bratisl Lek Listy 115: 611616, 2014

11 Wei XQ, Li X, Xin XJ and Tong ZS: Clinical features and survival analysis of very young $($ age $<35)$ breast cancer patients. Asian Pac J Cancer Prev 14: 5949-5952, 2013.

12 Bingham PM, Stuart SD and Zachar Z: Lipoic acid and lipoic acid analogs in cancer metabolism and chemotherapy. Expert Rev Clin Pharmacol 7: 837-846, 2014.

13 Kono Y, Inomata M, Hagiwara S, Hiratsuka T, Suzuki K, Koga $\mathrm{H}$, Shiraishi N, Noguchi T and Kitano S: Antiproliferative effects of a new $\alpha$-lipoic acid derivative, DHL-HisZnNa, in HT29 human colon cancer cells in vitro. Expert Opin Ther Targets 16: 103-109, 2012.

14 Puchsaka P, Chaotham C and Chanvorachote P: $\alpha$-Lipoic acid sensitizes lung cancer cells to chemotherapeutic agents and anoikis via integrin $\beta 1 / \beta 3$ downregulation. Int J Oncol 49: 14451456, 2016.

15 Alpay M, Yurdakok-Dikmen B, Kismali $G$ and Sel T: Antileukemic effects of piperlongumine and alpha lipoic acid combination on Jurkat, MEC1 and NB4 cells in vitro. J Cancer Res Ther 12: 556-560, 2016.

16 Feuerecker B, Pirsig S, Seidl C, Aichler M, Feuchtinger A, Bruchelt $\mathrm{G}$ and Senekowitsch-Schmidtke R: Lipoic acid inhibits cell proliferation of tumor cells in vitro and in vivo. Cancer Biol Ther 13: 1425-1435, 2012.
17 Richardson DR, Kalinowski DS, Lau S, Jansson PJ and Lovejoy DB: Cancer cell iron metabolism and the development of potent iron chelators as anti-tumor agents. Biochim Biophys Acta 1790: 702-717, 2009

$18 \mathrm{Ou} \mathrm{P}$, Tritschler HJ, Wolff SP: Thioctic (lipoic) acid: a therapeutic metal-chelating antioxidant? Biochem Pharmacol 50: 123-126, 1995.

19 Carlisi D, Buttitta G, Di Fiore R, Scerri C, Drago-Ferrante R, Vento $\mathrm{R}$ and Tesoriere G: Parthenolide and DMAPT exert cytotoxic effects on breast cancer stem-like cells by inducing oxidative stress, mitochondrial dysfunction and necrosis. Cell Death Dis 14: e2194, 2016.

20 Moon HS: Chemopreventive Effects of Alpha Lipoic Acid on Obesity-Related Cancers. Ann Nutr Metab 68: 137-144, 2016.

21 Papanas $\mathrm{N}$ and Ziegler D: Efficacy of $\alpha$-lipoic acid in diabetic neuropathy. Expert Opin Pharmacother 15: 2721-2731, 2014.

22 Bence KK, Delibegovic M, Xue B, Gorgun CZ, Hotamisligil GS, Neel BG and Kahn BB: Neuronal PTP1B regulates body weight, adiposity and leptin action. Nat Med 12: 917-924, 2006.

23 Zhu S, Bjorge JD and Fujita DJ: PTP1B contributes to the oncogenic properties of colon cancer cells through Src activation. Cancer Res 67: 10129-10136, 2007.

24 Desideri I, Francolini G, Becherini C, Terziani F, Delli Paoli C, Olmetto E, Loi M, Perna M, Meattini I, Scotti V, Greto D, Bonomo P, Sulprizio S and Livi L: Use of an alpha lipoic, methylsulfonylmethane and bromelain dietary supplement $\left(\right.$ Opera $\left.{ }^{\circledR}\right)$ for chemotherapy-induced peripheral neuropathy management, a prospective study. Med Oncol 34: 46, 2017.

Received March 3, 2017

Revised May 9, 2017

Accepted May 10, 2017 